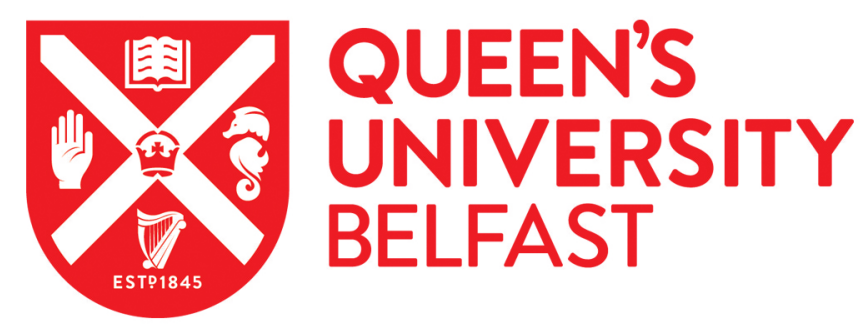

\title{
An Innovative Portable Biosensor System for the Rapid Detection of Freshwater Cyanobacterial Algal Bloom Toxins
}

Bickman, S., Campbell, K., Elliott, C. T., Murphy, C. S., O'Kennedy, R. J., Papst, P., \& Lochhead, M. (2018). An Innovative Portable Biosensor System for the Rapid Detection of Freshwater Cyanobacterial Algal Bloom

Toxins. Environmental science \& technology, 1-27. https://doi.org/10.1021/acs.est.8b02769

Published in:

Environmental science \& technology

Document Version:

Peer reviewed version

Queen's University Belfast - Research Portal:

Link to publication record in Queen's University Belfast Research Portal

Publisher rights

Copyright 2018 ACS This work is made available online in accordance with the publisher's policies. Please refer to any applicable terms of use of the publisher.

\section{General rights}

Copyright for the publications made accessible via the Queen's University Belfast Research Portal is retained by the author(s) and / or other copyright owners and it is a condition of accessing these publications that users recognise and abide by the legal requirements associated with these rights.

Take down policy

The Research Portal is Queen's institutional repository that provides access to Queen's research output. Every effort has been made to ensure that content in the Research Portal does not infringe any person's rights, or applicable UK laws. If you discover content in the Research Portal that you believe breaches copyright or violates any law, please contact openaccess@qub.ac.uk. 


\section{An Innovative Portable Biosensor System for the Rapid \\ Detection of Freshwater Cyanobacterial Algal Bloom Toxins}

Sarah Bickman, Katrina Campbell, Christopher T. Elliott, Caroline S Murphy, Richard J. O'Kennedy, Philip Papst, and Michael Lochhead

Environ. Sci. Technol., Just Accepted Manuscript • DOI: 10.1021/acs.est.8b02769 • Publication Date (Web): 13 Sep 2018

Downloaded from http://pubs.acs.org on September 18, 2018

Just Accepted

"Just Accepted" manuscripts have been peer-reviewed and accepted for publication. They are posted online prior to technical editing, formatting for publication and author proofing. The American Chemical Society provides "Just Accepted" as a service to the research community to expedite the dissemination of scientific material as soon as possible after acceptance. "Just Accepted" manuscripts appear in full in PDF format accompanied by an HTML abstract. "Just Accepted" manuscripts have been fully peer reviewed, but should not be considered the official version of record. They are citable by the Digital Object Identifier (DOIß). "Just Accepted" is an optional service offered to authors. Therefore, the "Just Accepted" Web site may not include all articles that will be published in the journal. After a manuscript is technically edited and formatted, it will be removed from the "Just Accepted" Web site and published as an ASAP article. Note that technical editing may introduce minor changes to the manuscript text and/or graphics which could affect content, and all legal disclaimers and ethical guidelines that apply to the journal pertain. ACS cannot be held responsible for errors or consequences arising from the use of information contained in these "Just Accepted" manuscripts.

\section{ACS Publications}




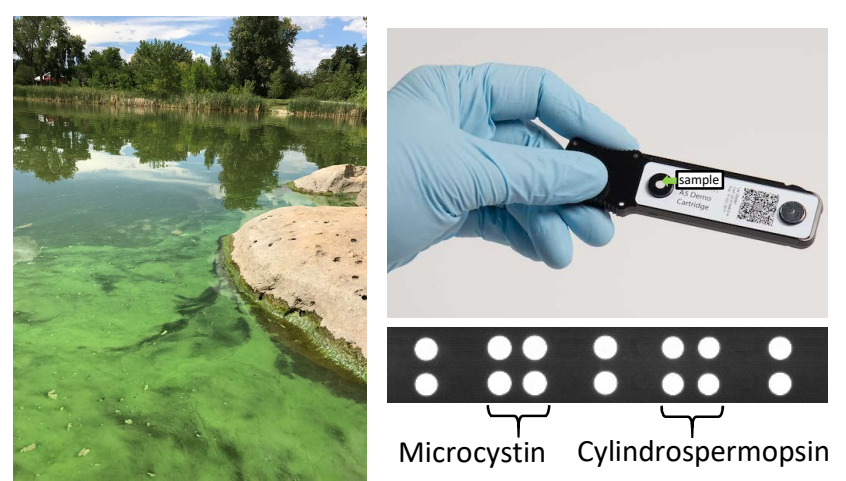




\section{An Innovative Portable Biosensor System for the Rapid}

\section{Detection of Freshwater Cyanobacterial Algal Bloom Toxins}

3 Sarah R. Bickman*1, Katrina Campbell ${ }^{2}$, Christopher Elliott ${ }^{2}$, Caroline Murphy ${ }^{3}$, Richard O’Kennedy $^{3}$,

$4 \quad$ Philip Papst ${ }^{1}$, Michael J. Lochhead ${ }^{1}$

5

$6 \quad{ }^{1}$ MBio Diagnostics, Inc., 5603 Arapahoe Ave, Boulder, CO 80303

$7 \quad{ }^{2}$ Institute for Global Food Security, School of Biological Sciences, Queen's University, Belfast,

8 Stranmillis Road, Belfast, United Kingdom, BT9 5AG.

$9{ }^{3}$ School of Biotechnology, National Centre for Sensor Research and Biomedical Diagnostics Institute,

10 Dublin City University, Dublin 9, Ireland.

$11 *$ Corresponding author

12 Keywords: microcystin, cylindrospermopsin, algae, HAB, cyanotoxin, sensor, waveguide 


\section{ABSTRACT}

Harmful algal blooms in freshwater systems are increasingly common and present threats to

16 drinking water systems, recreational waters, and ecosystems. A highly innovative simple to use, portable

17 biosensor system (MBio) for the rapid and simultaneous detection of multiple cyanobacterial toxins in

18 freshwater is demonstrated. The system utilizes a novel planar waveguide optical sensor that delivers

19 quantitative fluorescent competitive immunoassay results in a disposable cartridge. Data are presented

20 for the world's first duplex microcystin (MC) / cylindrospermopsin (CYN) assay cartridge using a

21 combination of fluorophore-conjugated monoclonal antibodies as detector molecules. The on-cartridge

22 detection limits of $20 \%$ inhibitory concentration $\left(\mathrm{IC}_{20}\right)$ was $0.4 \mu \mathrm{g} / \mathrm{L}$ for $\mathrm{MC}$ and $0.7 \mu \mathrm{g} / \mathrm{L}$ for $\mathrm{CYN}$. MC

23 assay coverage of eight important MC congeners was demonstrated. Validation using 45 natural lake

24 water samples from Colorado and Lake Erie showed quantitative correlation with commercially available

25 laboratory-based enzyme linked immunosorbent assays. A novel cell lysis module was demonstrated

26 using cyanobacteria cultures. Results show equivalent or better performance than the gold-standard but

27 more tedious $3 \mathrm{X}$ freeze-thaw method, with $>90 \%$ cell lysis for laboratory cultures. The MBio system

28 holds promise as a versatile tool for multiplexed field-based cyanotoxin detection, with future analyte

29 expansion including saxitoxin, anatoxin-a, and marine biotoxins. 


\section{INTRODUCTION}

Harmful Algal Blooms (HABs) caused by cyanobacteria are increasing in frequency and duration

33 and constitute a public health threat in addition to causing substantial economic losses, ecological

34 damage, and food supply concerns ${ }^{1}$. Recent events in the United States demonstrated significant impacts

35 on drinking water systems (Toledo, $2014^{2}$ ), recreational waters (Florida, 2016 ${ }^{3}$ ), and public health (Utah,

$362016^{4}$ ). The World Health Organization (WHO) and the US Environmental Protection Agency (EPA)

37 have established guidelines for toxin levels in drinking water. The WHO has established a guideline that

drinking water should have less than $1 \mu \mathrm{g} / \mathrm{L}$ of microcystin-leucine-arginine (MC-LR) including both free and intracellular toxin 5 . In 2016 the US Environmental Protection Agency (EPA) developed health advisories for toxins from cyanobacteria and recommended $\leq 0.3 \mu \mathrm{g} / \mathrm{L}$ for $\mathrm{MCs}$ and $\leq 0.7 \mu \mathrm{g} / \mathrm{L}$ for cylindrospermopsin $(\mathrm{CYN})$ for children under 6 years of age and $\leq 1.6 \mu \mathrm{g} / \mathrm{L}$ of $\mathrm{MC}$ and $\leq 3.0 \mu \mathrm{g} / \mathrm{L}$ of CYN for anyone above 6 years of age ${ }^{6,7}$. The US EPA also recently released draft Ambient Water Quality Criteria (AWQC) / Swimming Advisory levels at 4 and $8 \mu \mathrm{g} / \mathrm{L}$ for $\mathrm{MC}$ and $\mathrm{CYN}^{8}$, respectively.

Similarly, in the EU the European Commission has issued a proposal for a recast of Directive 98/83/EC to have a revised Directive on the quality of water intended for human consumption whereby MC-LR is included as a chemical parameter with a parametric value of $1 \mu \mathrm{g} / \mathrm{L}^{9}$.

Fluorometric detection of phycocyanin and chlorophyll pigments can provide useful information on algal bloom composition and biomass, but these measurements do not indicate whether a bloom is

49 producing toxin, which can vary with species, strain or sub-population ${ }^{10}$, growth stage, and environmental

50 conditions $^{11}$. Toxin detection is generally based on laboratory methods, which means samples must be

51 collected, packaged, and shipped to reference laboratories for testing. Laboratory methods for

52 cyanobacterial toxin detection ${ }^{12}$ include Enzyme-Linked ImmunoSorbent Assay (ELISA) ${ }^{13-16}$, protein

53 phosphatase inhibition assay ${ }^{17-21}$, liquid chromatography / mass spectrometry (LC/MS) ${ }^{22-26}$, micro-sphere

54 flow cytometry ${ }^{27}$, and mouse bioassay ${ }^{28,29}$. Field-portable strip tests are available, but the strip tests are 55 qualitative, only test for one toxin at a time, and require several user steps. As a result, there is a 
56 significant and unmet need for a rapid, easy-to-use, field-portable system for real time monitoring of

$57 \quad \mathrm{HAB}$ toxins offering high performance, semi-quantitative results and multiplexed detection comparable to

58 state-of-the-art laboratory methods. MBio Diagnostics is developing a cost-effective platform

59 technology designed to meet these needs.

MBio uses a novel method of combining planar waveguide illumination, fluorescence imaging, and microarray technology to deliver a multiplexed fluorescence immunoassay. The core technology is

62 based on simple disposable cartridges analyzed on a portable reader. The research community has been

63 using the MBio technology to develop assays for multiplexed HAB toxin detection in freshwater and

64 marine systems ${ }^{24,30-33}$. McNamee et al. demonstrated a 5-plex toxin assay that included a combination of

65 freshwater (MC, CYN) and marine biotoxins (saxitoxin, domoic acid, okadaic acid) ${ }^{30}$. Murphy et al.

66 demonstrated sensitive, quantitative, reproducible MC detection using recombinant antibodies on the

67 platform ${ }^{32}$. Devlin et al. combined a novel sample preparation method with MC detection ${ }^{24}$. Additional

68 research has demonstrated toxin and other small molecule detection in marine samples ${ }^{31}$, fish tissue ${ }^{33}$, and

69 milk matrices ${ }^{34}$.

This study builds on that body of work and advances the platform by significantly simplifying the

71 assay workflow whilst maintaining quantitative assay performance. The aim of this study is to

72 demonstrate a one-step, 10-minute, duplex MC/CYN assay, which can be combined with a simple, 10-

73 minute field-portable mechanical lysis method, enabling rapid, on-site detection of dissolved or total

74 toxins. Together, these methods allow for the first demonstration of a field-portable, semi-quantitative

75 duplex assay.

\subsection{MBio Cartridge and Reader}

The MBio platform is a novel, patent-protected system that uses planar waveguide and microarray technology to deliver a sensitive, multiplexed fluorescence assay in a simple fluidic cartridge.

79 Fig. 1 provides a schematic of the core elements of the system, which is referred to as LightDeck ${ }^{\circledR}$

80 technology. A solid-state diode laser $(639 \mathrm{~nm})$ is used as the illumination source. The cartridge integrates 
81 a laser light-coupling lens into the injection molded plastic waveguide, which couples and launches the

82 laser light down the plastic substrate. The multimode waveguide generates an evanescent illumination

83 field at the solid assay surface. By printing a spatial array of capture spots on the assay surface of the

84 waveguide, the system enables multiple spot assays to be run simultaneously in every cartridge.

85 Evanescent field illumination makes the system relatively insensitive to the solution phase components

86 above the assay surface. This enables assays to be conducted in the presence of complex sample matrices

87 without requiring wash steps. The simplicity of the MBio LightDeck ${ }^{\circledR}$ technology makes the system

88 robust yet inexpensive.

Simultaneous MC and CYN competitive immunoassays are run in each single-sample fluidic

90 cartridge, illustrated schematically in Fig. 2. Toxin-protein conjugates are printed on the assay surface of

91 the waveguide in a two-dimensional array using non-contact microarray printing. The detection reagent

92 is a lyophilized mixture of fluorescently labeled antibodies against MC and CYN that is rehydrated

93 with the sample. By directly conjugating the primary detection antibodies with fluorophore, a one-

94 step, multiplexed immunoassay is enabled. There is no need for anti-species detection antibodies,

95 enzyme

conjugates, washes, color detection or stop solutions. Further, the lyophilized detection reagent contains a proprietary mix of salts, buffers, and blocker molecules that mitigate the effects of variability in raw water samples. Finally, lyophilizing the detection reagent improves the long-term packaged stability.

To measure the toxin contained in a filter or extracted sample, add it to the lyophilized detection reagent, aspirate/dispense, immediately transfer to the MBio cartridge, and insert the cartridge into the

101 reader. The reader will automatically perform the assay by releasing the sample mixture down a fluidic

102 channel. In the absence of toxin in the sample, the antibodies bind to the MC- and CYN-conjugate spots

103 on the surface yielding bright spots on the microarray. When toxin is present, antibody binding to the

104 conjugate spots is competitively inhibited and the fluorescence signal is reduced. Custom software

105 performs all spot finding and image analysis and converts image data into a quantitative output. 
106 Cartridges are factory-calibrated; unlike ELISA, users do not have to generate calibration curves with 107 each sample run. Calibration curves for each cartridge lot are loaded into system software, which allows 108 a single cartridge to deliver a quantitative $(\mu \mathrm{g} / \mathrm{L})$ output for both $\mathrm{MC}$ and $\mathrm{CYN}$. This factory calibration 109 accounts for small variations in spot intensity between lots. Packaged cartridges are shelf-stable and 110 remain calibrated for months. The quantitative result is accurate for the MC-LR and CYN congeners.

111 The assays, however, do not differentiate between congeners and the quantitative output depends on 112 congener cross-reactivity, discussed in more detail below.

\section{$113 \quad 1.2$ Portable Lysis Module}

Algal cells that produce intracellular toxins must be lysed to determine total toxin (dissolved and

115 particulate). Freezing and thawing the sample three times ( $3 \mathrm{X}$ freeze thaw) is the gold standard

116 laboratory method, but this is not a field-portable option and is time-consuming when running single

117 samples in the lab. Devlin et al. described a simple, effective method that combined glass beads with a 118 milk frother for mechanical cell lysis ${ }^{24}$. MBio has significantly improved this method by eliminating all

119 filtration and pre-concentration steps and modifying the mixing head to improve lysis efficacy. The result

120 is a battery-operated mechanical lysis module that efficiently lyses $5 \mathrm{~mL}$ raw water samples in 10 minutes

121 without any hands-on time from the operator. The method is simple and environmentally friendly, as

122 there are no lysis chemicals required.

1242 MATERIALS AND METHODS

\section{$125 \quad 2.1$ Materials}

Antibodies and Toxin-Protein Conjugates. The MC and CYN competitive immunoassays use

127 proprietary murine monoclonal antibodies (mAbs) sourced from Xenobics Limited (Belfast, Northern

128 Ireland). For microcystin, the immunogen was an intact MC-LR conjugated to bovine serum albumin ${ }^{35}$.

129 Although the antibody was raised against the LR variant, clone selection was based in part on cross-

130 reactivity against other MC congeners. The antibody to cylindrospermopsin was raised to 
131 cylindrospermopsin conjugated to keyhole limpet hemocyanin as the immunogen ${ }^{13}$. For the one-step

132 assay format, the MC and CYN mAbs were directly labelled with the fluorescent dye $\mathrm{CF}^{\circledR} 640 \mathrm{R}$ (Biotium)

133 using NHS chemistry. Purification was performed with size exclusion chromatography spin columns to

134 remove excess unbound dye (Amicon, Zeba). The purified dye-labeled antibody was then diluted to a

135 stock concentration in a storage buffer ( $1 \mathrm{x}$ PBS, $10 \mathrm{mg} / \mathrm{mL}$ BSA, $0.02 \% \mathrm{v} / \mathrm{v}$ Tween-20) containing

136 preservative (Proclin 300).

137 Microcystin- and cylindrospermopsin-ovalbumin (OVA) conjugates used for array printing were 138 purchased from Xenobics.

Toxin Reference Standards. Certified reference materials dissolved in methanol were purchased

140 for MC-LR, MC-RR, nodularins (NODR), dM MC-LR and CYN from the National Research Council of

141 Canada (NRCC). MC-LA, MC-LF, MC-YR, and MC-LW were purchased from Enzo Life Sciences and

142 were reconstituted in methanol according to the product data sheets. Further dilutions of all reference

143 materials were performed with reagent water.

144 Water, Buffers, and Other Reagents. The term reagent water refers to RNase-free, DNase-free, 145 protease-free bottled laboratory water sourced commercially from Sigma Aldrich or ThermoFisher 146 Scientific. Phosphate buffered saline (PBS), Tween-20, Saponin, Triton 100-X, Polymyxin B, Lugol's

147 iodine, and bovine serum albumin (BSA) were purchased from Sigma Aldrich.

\subsection{Algal Culture}

Two strains of Microcystis aeruginosa (LB 2385, LB 2063) and one strain of Cylindrospermopsis

150 sp. (LB 942) were purchased from the Culture Collection of Algae at the University of Texas at Austin

151 (UTEX). One strain of Cylindrospermopsis sp. (CS506) that produces CYN was supplied by Bowling

152 Green State University. Microcystis LE3 cultures were provided by the National Center for Coastal

153 Ocean Science (NOAA, Charleston, SC). All glassware and media were autoclave sterilized prior to use.

154 Inoculation and all culture handling procedures were performed in a sterile Class II biosafety cabinet.

155 Cultures were maintained at $20^{\circ} \mathrm{C} \pm 2{ }^{\circ} \mathrm{C}$ on a $16: 8 \mathrm{~h}$ light:dark cycle (light levels were $0.3 \times 10^{16}$ 
156 quanta/sec/ $\mathrm{cm}^{2}$ ) in sterile BG-11 medium purchased from UTEX or WC medium. Every three weeks, 2 $157 \mathrm{~mL}$ of culture were withdrawn and added to $200 \mathrm{~mL}$ of medium and allowed to grow for between 3-6

158 weeks prior to use in experiments. The exponential growth phase occurs for approximately 1 week before 159 entering a stationary phase.

\subsection{Lake Water Samples}

Lake water samples were collected from several sources in Colorado (USA) and from locations on Lake Erie (USA) during July and August 2017. Colorado water samples were sourced with the 163 cooperation of water utilities in the cities of Boulder, Aurora, Thornton, and Westminster. [It should be 164 noted that none of the water sources used for drinking water in Colorado had detectible toxins in this 165 study.]. Through cooperation with the City of Northglenn, Colorado, samples from an active bloom in a 166 retention pond were collected. Other samples with active blooms were collected from unused storage 167 ponds in Thornton. Samples were also collected from an active bloom in a private pond in Boulder with 168 permission. Lake Erie samples were collected at sampling stations near Toledo, Ohio in collaboration with the University of Toledo, and from sampling stations in Sandusky Bay in collaboration with Bowling Green State University.

All samples were collected in glass containers. Colorado lake water samples were measured on 172 the day of collection as fresh samples, then aliquots were frozen at $-20{ }^{\circ} \mathrm{C}$ for later testing. Lake Erie 173 samples were shipped frozen in glass containers.

\subsection{Sample Preparation (Lysis)}

Cell lysis via $3 \mathrm{X}$ freeze-thaw was performed per EPA Method $546^{36}$. For the MBio portable lysis

176 module, a $5 \mathrm{~mL}$ natural water or culture sample was added to a clean 1-ounce glass jar containing $5 \mathrm{~g}$ of $177 \quad 0.1-0.15 \mathrm{~mm}$ glass beads. The sample was then agitated with a custom-designed battery operated mixer 178 for 10 minutes. After the motor stops, beads immediately settle to the bottom of the sample. Sample for 179 the assay was withdrawn via pipet transfer from the layer of liquid above the beads and below the foam 180 generated by frothing, and immediately transferred to the tube containing dried reagents, mixed with the 
181 reagents, and then added to the cartridge. This method is a simplification of the previously published

$182 \operatorname{method}^{24}$, where filtration and concentration steps were used. The simplified method presented here is 183 one that can be easily performed in the field.

Cell lysis efficiency was reported as percent lysis and was measured with light microscopy and manual cell counts were performed with a hemocytometer. Samples were mixed 1:1 with Lugol's iodine

186 before loading the hemocytometer. Cells in the central $25 \times 25$ squares in the hemocytometer were

187 counted for a total volume of $0.1 \mu \mathrm{L}$. If fewer than 400 cells were counted in this volume, additional 188 squares were counted to improve the counting statistics. With 400 counted cells, the statistical error was $1895 \%$.

\subsection{Array Printing and Cartridge Assembly}

MBio waveguides were injection-molded using a proprietary low autofluorescence polymer resin. Waveguides were activated with a custom plasma-silanization process prior to array printing. The fluidic channel was defined using a pressure-sensitive adhesive (PSA) gasket. Toxin-protein conjugates were printed to the waveguides using a non-contact arrayer (Scienion S11). Printed waveguides were washed, a blocker-stabilizer was applied, and an injection-molded plastic upper component was bonded via a pressure sensitive adhesive gasket with a pneumatic press to form the cartridge. Cartridges were packaged in barrier pouches with desiccant prior to use.

\subsection{MBio Assay Workflow}

$100 \mu \mathrm{L}$ of the prepared sample were added to the kit microtube containing dried reagents and mixed via pipet aspirate/dispense five times to ensure reagent rehydration. The mixed sample was then immediately transferred to the inlet port of the cartridge and the cartridge was inserted into the reader. The MBio reader automatically read the cartridge barcode, confirming assay type, authenticity, and expiration date. The user entered a sample name into the software interface and pressed "start" to initiate the measurement. The reader automatically released the sample-antibody mixture into the detection chamber containing the capture array. The assay was timed automatically, and after 10 minutes the 
206 proprietary software converted the array images into quantitative measured concentrations. In summary,

207 the user mixed the sample and reagents, loaded the cartridge, inserted it into the reader, entered the

208 sample name, and started the program. Hands-on assay time was less than one minute.

\subsection{Reference MC and CYN ELISAs}

As a reference, two competitive enzyme-linked immunosorbent assay (ELISA) kits were

211 purchased from Abraxis: Microcystins/Nodularins (ADDA) (P/N 520011OH) and Cylindrospermopsin

212 (P/N 522011). The kits were used in accordance with the manufacturer's instructions. The ADDA ELISA

213 is the reference immunoassay used in US EPA Method $546^{36}$.

\section{RESULTS AND DISCUSSION}

\section{$215 \quad 3.1$ Assay Analytical Performance}

216 When developing the MC and CYN assays on the MBio platform, several parameters were used to

217 "tune" the assay sensitivity. Assay time, toxin-protein print concentration, and detection antibody

218 concentration all influence the assay curve, with antibody concentration providing the strongest effect.

219 For this demonstration, an $\mathrm{IC}_{50}$ of $1 \mu \mathrm{g} / \mathrm{L}$ for the $\mathrm{MC}$ and $\mathrm{CYN}$ assays was targeted. By centering the

220 assay's detection range on $1 \mu \mathrm{g} / \mathrm{L}$, a sensitive assay relevant for field testing with various applications

221 (source waters, recreation, etc.) was delivered. It is important to note that assay sensitivity could be

222 further adjusted up or down by titration of the detection antibody concentration.

Analytical performance was based on the analysis of serial dilutions of certified reference materials into reagent water. The output intensities were normalized to the intensity at zero toxin $\left(\mathrm{B}_{0}\right)$ and are plotted in linear-log plots of $\mathrm{B} / \mathrm{B}_{0}$ versus toxin concentration. 4-parameter logistic fits were used to define max, min, and 50\% inhibitory concentration $\left(\mathrm{IC}_{50}\right)$. Fig. 3a provides a standard curve for the $\mathrm{MC}$ assay generated using MC-LR (NRCC standard) diluted into reagent water. $\mathrm{IC}_{50}$ is $1.1 \mu \mathrm{g} / \mathrm{L}$ and dynamic

229 generated using CYN (NRCC standard) diluted into reagent water. $\mathrm{IC}_{50}$ is $1.4 \mu \mathrm{g} / \mathrm{L}$ and dynamic range 230 reported as $\mathrm{IC}_{20}$ to $\mathrm{IC}_{80}$ was 0.7 to $2.7 \mu \mathrm{g} / \mathrm{L}$. 


\subsection{Microcystin Congener Coverage}

Although MC-LR is the congener used in most safety guidelines ${ }^{37}$, there are over 100 known congeners $^{38}$ of microcystin, most with unknown toxicities. To be useful as a field microcystin test, the

234 MBio assay must show good coverage across a range of $\mathrm{MC}$ congeners. To test coverage of a range of 235 common toxins, standard curves for 8 different congeners were run on the MBio assay. MC-LR, MC-

$236 \mathrm{RR}$, and MC-YR were chosen because they are the most common and toxic variants ${ }^{39}$ followed by MC237 LA, MC-LW, and MC-LF ${ }^{40}$. Nodularins, produced by Nodularia ${ }^{41}$, are structurally similar to MC.

$238\left[\mathrm{Dha}^{7}\right]$-microcystin-LR (dM MC-LR) is a cyclic peptide toxin also produced by cyanobacteria. Results 239 (see Fig. 4) show that although the $\mathrm{IC}_{50}$ was not the same for all congeners, the MBio assay provides 240 reasonable coverage for the 8 variants tested.

241 Using the same congener dilutions as on the MBio assay, calculated cross-reactivities on the ADDA242 ELISA were 100\%, 131\%, 167\%, and 53\% for NRCC standards MC-LR, dm MC-LR, NODR, and MC243 RR, respectively. Cross-reactivities for the Enzo toxins MC-LA, MC-LF, MC-YR, and MC-LW were $244133 \%, 96 \%, 96 \%$, and 100\%, respectively. Since the MBio MC mAb was developed with a MC-LR 245 conjugate as the immunogen, a different cross-reactivity profile is expected relative to an immunoassay 246 directed specifically against the ADDA moiety ${ }^{42,43}$. Variable cross-reactivities for all currently available 247 immunoassays (including MBio and the commercial ELISAs) could lead to either under-estimating or 248 over-estimating toxin concentrations depending on congeners in the sample $\mathrm{e}^{44}$. By selecting an $\mathrm{MC} \mathrm{mAb}$ 249 with reasonable congener cross-reactivity and standardizing against the highly toxic MC-LR congener, 250 MBio has developed a rapid, portable assay that should be broadly applicable for different toxin 251 producing blooms. Knowledge of congeners present in the sample, for example from LC/MS/MS data, 252 could be used to refine quantitative accuracy of the immunoassays. In particular, MBio software has the 253 ability to adjust calibrations if the dominant MC congener in the sample is known.

254 MBio did not test a range of CYN congeners. 7-deoxy-CYN is a known congener, but has low toxicity 255 compared to CYN. Although not tested on the MBio platform, the CYN antibody used in this study has 
256 been shown to have low cross reactivity to 7-deoxy-CYN. ${ }^{13}$ This is a potential advantage in a field testing 257 platform where the utility is with toxic variant detection.

\subsection{Cylindrospermopsin Producing Cell Culture}

259 Since natural water samples containing CYN were difficult to obtain at the time of this study, a CYN 260 producing cell culture (CS506) was diluted and measured on the MBio platform and compared to the 261 same dilution as measured on ELISA. 3X freeze thaw was used to lyse the cell culture prior to 262 measurement. There was direct correlation between the measured concentrations with one dilution 263 measuring $1.8 \pm 0.1 \mu \mathrm{g} / \mathrm{L}$ on the MBio platform and $1.91 \pm 0.04$ on ELISA. Similarly, another dilution 264 measured as $0.6 \pm 0.1 \mu \mathrm{g} / \mathrm{L}$ on the MBio platform and $0.61 \pm 0.02 \mu \mathrm{g} / \mathrm{L}$ on ELISA.

\section{$265 \quad 3.4$ Sample Preparation (Lysis)}

The MBio mechanical lysis module was demonstrated using cultures of three cyanobacterial strains 267 (UTEX 2385, UTEX 2063, and UTEX 942) and results are shown in Table 1. Microscopy was used to quantify cell lysis. Table 1 results show that cell lysis efficiency of the MBio module was equivalent or superior to the standard three freeze-thaw method for these cultured cells. In addition, MC toxin levels were measured before and after cell lysis with the toxin producing Microcystis cultures UTEX 2385 and LE3 and the measured toxin levels increased significantly after cell lysis. For example, prior to lysis the LE3 cell culture measured MC at $44 \mu \mathrm{g} / \mathrm{L}$ and after lysis it was $410 \mu \mathrm{g} / \mathrm{L}$.

Since natural blooms have cell morphology and colony structure different from that encountered in

274 laboratory cultures, it was important to test the lysis method with naturally occurring algae. Scum

275 samples from a storage pond containing Microcystis, Anabaena, and Aphanizomenon were collected and 276 measured on the day of collection. No toxin was detected prior to lysis. After 10-minute lysis on the 277 MBio system, MC concentration was $25 \mu \mathrm{g} / \mathrm{L}$. The same sample run after $3 \mathrm{x}$ freeze-thaw gave $22 \mu \mathrm{g} / \mathrm{L}$

278 MC. Cell counts were performed prior to lysis, after lysis with the MBio mechanical cell lysis method, 279 and after $3 \mathrm{X}$ freeze thaw. Results are presented in Table 2 and demonstrate that the mechanical method is 280 equivalent to $3 \mathrm{X}$ freeze thaw. 


\subsection{Comparison of Natural Lake Water Samples Measured with MBio and ELISA}

Natural water samples were run on the MBio MC/CYN duplex assay and in parallel on the ADDAELISA and CYN-ELISA assays. Nine samples from Colorado drinking water reservoirs showed no detectable toxin on either assay. This is an important first step in establishing specificity of the MBio assay

in natural samples. Two scum samples from a retention pond with an active bloom were phenotypically

287 identified to contain mixed colonies of Microcystis aeruginosa and Anabaena. Both samples showed 288 very high MC toxin levels on MBio and ADDA-ELISA. 20-fold dilutions were required to bring samples 289 into quantitative range. Good correlation was observed between MBio and ELISA. Scum sample 1 290 yielded $16 \mu \mathrm{g} / \mathrm{L}$ total MC on MBio and $20 \mu \mathrm{g} / \mathrm{L}$ total MC on ADDA-ELISA. Scum sample 2 yielded $>80$

$291 \mu \mathrm{g} / \mathrm{L}$ total MC on both MBio and ADDA-ELISA. A second pond bloom was phenotypically suggestive 292 of Euglena and Peridinium, neither

293 of which are expected to produce MC or CYN. Neither toxin was detected on the MBio or ADDA-

294 ELISA assays. Importantly, this result demonstrates that despite the high cell load of $4 \times 10^{9}$ cells/L, the 295 rapid, no-wash MBio assay did not report false positives for toxin.

Thirteen samples from stations across the western basin of Lake Erie were run on the MBio

$297 \mathrm{MC} / \mathrm{CYN}$ assay and in parallel on the ADDA-ELISA and CYN-ELISA. These sample were shipped 298 frozen to MBio, and a 3X freeze-thaw protocol per US EPA Method $546^{36}$ was run prior to splitting the 299 samples onto the respective platforms. None of the samples showed detectable CYN on either MBio or 300 the commercial ELISA. Table 3 provides a summary of MC results. Samples that were expected to 301 contain significant toxin levels were measured with a 1:10 dilution. Sample 7M, week 0 was not 302 expected to contain the significant toxin levels, so it was only run neat at the time of the study. These 303 data show good quantitative correlation between the MBio assay and the ADDA-ELISA $\left(\mathrm{R}^{2}=0.78\right)$. 

parallel ADDA-ELISA and CYN-ELISA assays. Again, none of these samples showed detectable CYN on either assay. MC results are provided in Table 4. Data show that while there is overall correlation between MBio MC/CYN and ADDA-ELISA (e.g, low toxin to high toxin, $\mathrm{R}^{2}=0.85$ ), MBio shows lower total $\mathrm{MC}$ relative to the ADDA-ELISA assay. The Sandusky samples were tested at the same time as the western Lake Erie samples, so the offset is not expected to be the result of laboratory or operator differences. Sandusky Bay is expected to have a diverse bloom profile, with Microcystis

311 aeruginosa, Planktothrix, and other toxin producers possible (personal communication, George

312 Bullerjahn). An explanation for the lower total MC concentrations could therefore be the result of 313 different congener reactivities for MBio MC/CYN system relative to the ADDA-ELISA. In the absence 314 of specific congener profiles and quantification, it cannot be determined a priori which measurement is 315 the most accurate. We also note that there is discussion in the literature that the ADDA-ELISA could 316 inherently over-report total MC concentrations given the sensitivity to free ADDA due to degraded $317 \operatorname{toxin}^{44,45}$. Results presented in this manuscript demonstrate that a rapid, highly sensitive multiplex assay has

319 been developed for the semi-quantitative, simultaneous screening of MC and CYN cyanotoxins.

320 Monitoring programs for HAB biotoxins are increasingly becoming a necessity because of the potential 321 dangers to human health and significant economic impacts. As monitoring in other areas such as food 322 safety moves towards the implementation of methods based on performance criteria and harmonization of 323 standards that are fit-for purpose and adaptable in suitability for end users, there is scope for alternative 324 procedures and technologies. The MBio platform has shown the potential to offer next generation HAB 325 toxin monitoring with a multiplex assay system that goes beyond current state-of-the-art detection and has 326 the flexibility to incorporate additional biotoxins of concern without modifying the workflow. The next 327 step would be a full comparison with state of the art LC-MS methods, but the drawbacks would be in the 328 limited selection of analytical standard congeners available for a full quantitative comparison. 
Safety. MBio staff are trained in the safe handling of biohazards. Toxin-producing algal cultures were

330 handled in a certified biosafety cabinet in MBio's Biosafety Level 2 laboratory. Undiluted toxin stocks

331 were handled in a chemical fume hood.

\section{Acknowledgements}

This material is based upon work supported by the National Science Foundation under Grant No.

1621951. MBio system development was also supported by the National Science Foundation under Grant

No. OCE-1440299 and the Science Foundation Ireland under Grant number 14/IA/2646. The authors are

337 for important technical contributions to this study. The authors also gratefully acknowledge important

338 technical inputs on the Lake Erie samples from Drs. Timothy Davis and George Bullerjahn at Bowling

339 Green State University and Dr. Thomas Bridgeman and Brenda Snyder at the University of Toledo.

340 Finally, the authors are grateful to water quality experts from the cities of Aurora, Boulder, Northglenn,

341 Thornton and Westminster, Colorado for assistance in sample collection.

\section{AUTHOR INFORMATION}

343 Corresponding Author

344 *Phone +1 (303) 952-2836; fax +1 (303) 951-1529; e-mail: sarah.bickman@mbiodx.com

$345 \quad$ Notes

346 MBio Diagnostics, Inc. is a commercial organization. SRB, PP, and MJL are employees of MBio

347 Diagnostics.

\section{References}

349 1. Office of Water Environmental Protection Agency, Impacts of Climate Change on the Occurrence of $350 \quad$ Harmful Algal Blooms, EPA 820-S-13-001. 2013.

351 2. Lee, J. J., Driven by Climate Change, Algae Blooms Behind Ohio Water Scare Are New Normal. Nat 352 Geo August 6, 2014. 
353 3. Parker, L., Slimy Green Beaches May Be Florida's New Normal. Nat Geo July 27, 2016, 2016.

354 4. Huge Toxic Algae Bloom Sickens More than 100 in Utah Amid Heatwave. The Guardian July 22, $355 \quad 2016$.

356 5. World Health Organization Guidelines for Drinking-water Quality.

357 http://apps.who.int/iris/bitstream/10665/44584/1/9789241548151_eng.pdf

358 6. Environmental Protection Agency, Drinking Water Health Advisory for the Cyanobacterial 359 Microcystin Toxins. 2015.

360 7. Environmental Protection Agency, Drinking Water Health Advisory for the Cyanobacterial Toxin $361 \quad$ Cylindrospermopsin. 2015.

362 8. Office of Water Environmental Protection Agency, Fact Sheet: Draft Human Health Recreational 363 Ambient Water Quality Criteria/Swimming Advisories for Microcystins and Cylindrospermopsin. 3642016.

3659 . Cyanocost Microcystin-LR included in the proposed revision of the Drinking Water Directive. https://cyanocost.wordpress.com/2018/02/10/microcystin-lr-included-in-the-proposed-revision-ofthe-drinking-water-directive/ (May 11, 2018).

10. O’Neil, J. M.; Davis, T. W.; Burford, M. A.; Gobler, C. J., The rise of harmful cyanobacteria blooms: 369 The potential roles of eutrophication and climate change. Harmf Algae 2012, 14, 313-34.

11. Pimentel, J. S.; Giani, A., Microcystin production and regulation under nutrient stress conditions in toxic microcystis strains. Appl Environ Microbiol 2014, 80, (18), 5836-43.

12. Merel, S.; Walker, D.; Chicana, R.; Snyder, S.; Baures, E.; Thomas, O., State of knowledge and concerns on cyanobacterial blooms and cyanotoxins. Environ Int 2013, 59, 303-27.

13. Elliott, C. T.; Redshaw, C. H.; George, S. E.; Campbell, K., First development and characterisation of polyclonal and monoclonal antibodies to the emerging fresh water toxin cylindrospermopsin. Harmf Algae 2013, 24, 10-19.

14. Lindner, P.; Molz, R.; Yacoub-George, E.; Dürkop, A.; Wolf, H., Development of a highly sensitive inhibition immunoassay for microcystin-LR. Anal Chim Acta 2004, 521, (1), 37-44. 
15. Mountfort, D. O.; Holland, P.; Sprosen, J., Method for detecting classes of microcystins by combination of protein phosphatase inhibition assay and ELISA: comparison with LC-MS. Toxico 2005, 45, (2), 199-206.

16. Pyo, D.; Lee, J.; Choi, E., Trace analysis of microcystins in water using enzyme-linked immunosorbent assay. Microchem J 2005, 80, (2), 165-69.

17. Almeida, V. P. S., Cogo, K, S. Tsai, Moon, D. H., Colorimetric test for the monitoring of microcystins in cyanobacterial culture and enviornmental samples from the southeast Brazil. Brazilian J Microb 2006, 37, 192-98.

18. Bouaicha, N.; Maatouk, I.; Vincent, G.; Levi, Y., A colorimetric and fluorometric microplate assay for the detection of microcystin-LR in drinking water without preconcentration. Food Chem Toxicol 2002, 40, (11), 1677-83.

19. Heresztyn, T.; Nicholson, B. C., Determination of cyanobacterial hepatotoxins directly in water using a protein phosphatase inhibition assay. Water Res 2001, 35, (13), 3049-56.

20. Ortea, P. M.; Allis, O.; Healy, B. M.; Lehane, M.; Ni Shuilleabhain, A.; Furey, A.; James, K. J., Determination of toxic cyclic heptapeptides by liquid chromatography with detection using ultraviolet, protein phosphatase assay and tandem mass spectrometry. Chemosphere 2004, 55, (10), 1395402.

21. Rapala, J.; Erkomaa, K.; Kukkonen, J.; Sivonen, K.; Lahti, K., Detection of microcystins with protein phosphatase inhibition assay, high-performance liquid chromatography-UV detection and enzymelinked immunosorbent assay: Comparison of methods. Anal Chim Acta 2002, 466, (2), 213-31.

22. Beltran, E.; Ibanez, M.; Sancho, J. V.; Hernandez, F., Determination of six microcystins and nodularin in surface and drinking waters by on-line solid phase extraction-ultra high pressure liquid chromatography tandem mass spectrometry. J Chromatog. A 2012, 1266, 61-8.

23. Blahova, L.; Oravec, M.; Marsalek, B.; Sejnohova, L.; Simek, Z.; Blaha, L., The first occurrence of the cyanobacterial alkaloid toxin cylindrospermopsin in the Czech Republic as determined by immunochemical and LC/MS methods. Toxico 2009, 53, (5), 519-24. 
24. Devlin, S.; Meneely, J. P.; Greer, B.; Greef, C.; Lochhead, M. J.; Elliott, C. T., Next generation planar waveguide detection of microcystins in freshwater and cyanobacterial extracts, utilising a novel lysis method for portable sample preparation and analysis. Anal Chim Acta 2013, 769, 108-13.

25. Gallo, P.; Fabbrocino, S.; Cerulo, M. G.; Ferranti, P.; Bruno, M.; Serpe, L., Determination of cylindrospermopsin in freshwaters and fish tissue by liquid chromatography coupled to electrospray ion trap mass spectrometry. Rapid Comm Mass Spec : RCM 2009, 23, (20), 3279-84.

26. Guzman-Guillen, R.; Prieto, A. I.; Gonzalez, A. G.; Soria-Diaz, M. E.; Camean, A. M., Cylindrospermopsin determination in water by LC-MS/MS: optimization and validation of the method and application to real samples. Environ Toxicol Chem 2012, 31, (10), 2233-8.

27. Fraga, M.; Vilarino, N.; Louzao, M. C.; Rodriguez, L. P.; Alfonso, A.; Campbell, K.; Elliott, C. T.; Taylor, P.; Ramos, V.; Vasconcelos, V.; Botana, L. M., Multi-detection method for five common microalgal toxins based on the use of microspheres coupled to a flow-cytometry system. Anal Chim Acta 2014, 850, 57-64.

28. Falconer, I. R., Measurement of toxins from blue-green algae in water and foodstuffs. Academic Press, London, UK, 1993; p 165-75.

29. Kaushik, R.; Balasubramanian, R., Methods and Approaches Used for Detection of Cyanotoxins in Environmental Samples: A Review. Crit Rev in Environ Sci \& Tech 2013, 43, (13), 1349-83.

30. McNamee, S. E.; Elliott, C. T.; Greer, B.; Lochhead, M.; Campbell, K., Development of a planar waveguide microarray for the monitoring and early detection of five harmful algal toxins in water and cultures. Environ Sci \& Tech 2014, 48, (22), 13340-9.

31. Meneely, J. P.; Campbell, K.; Greef, C.; Lochhead, M. J.; Elliott, C. T., Development and validation of an ultrasensitive fluorescence planar waveguide biosensor for the detection of paralytic shellfish toxins in marine algae. Biosens \& Bioelec 2013, 41, 691-7.

32. Murphy, C.; Stack, E.; Krivelo, S.; McPartlin, D. A.; Byrne, B.; Greef, C.; Lochhead, M. J.; Husar, G.; Devlin, S.; Elliott, C. T.; O'Kennedy, R. J., Detection of the cyanobacterial toxin, microcystin-LR, 
using a novel recombinant antibody-based optical-planar waveguide platform. Biosensors \& Bioelec 2015, 67, 708-14.

33. Reverte Calvet, L.; Campàs, M.; Yakes, B. J.; Deeds, J. R.; Katikou, P.; Kawatsu, K.; Lochhead, M.; Elliott, C. T.; Campbell, K., Tetrodotoxin detection in puffer fish by a sensitive planar waveguide immunosensor. Sen \& Act B-Chem 2017, 253, 967-76.

34. McGrath, T. F.; McClintock, L.; Dunn, J. S.; Husar, G. M.; Lochhead, M. J.; Sarver, R. W.; Klein, F. E.; Rice, J. A.; Campbell, K.; Elliott, C. T., Development of a rapid multiplexed assay for the direct screening of antimicrobial residues in raw milk. Anal Bioanal Chem 2015, 407, (15), 4459-72.

35. Devlin, S.; Meneely, J. P.; Greer, B.; Campbell, K.; Vasconcelos, V.; Elliott, C. T., Production of a broad specificity antibody for the development and validation of an optical SPR screening method for free and intracellular microcystins and nodularin in cyanobacteria cultures. Talanta 2014, 122, 8-15.

36. Zaffiro, A., Laira Rosenblum, Steven Wendelken, Method 546: Determination of Total Microcystins and Nodularins in Drinking Water and Ambient Water by Adda Enzyme-Linked Immunosorbent Assay.

37. Environmental Protection Agency Nutrient Policy and Data Guidelines and Recommendations. https://www.epa.gov/nutrient-policy-data/guidelines-and-recommendations Microcystis bloom from an Algerian lake. Environ Poll 2016, 216, 836-44.

39. van Apeldoorn M. E.; van Egmond H. P.; Speijers Gerrit J. A..; Bakker Guido J. I., Toxins of cyanobacteria. Molec Nut \& Food Res 2007, 51, (1), 7-60.

40. Kfir, R.; Johannsen, E.; Botes, D. P., Monoclonal antibody specific for cyanoginosin-LA: preparation and characterization. Toxico 1986, 24, (6), 543-52.

452 41. Rinehart, K. L.; Namikoshi, M.; Choi, B. W., Structure and biosynthesis of toxins from blue-green 453 algae (cyanobacteria). J App Phycol 1994, 6, (2), 159-76. 
454 42. Fischer, W. J.; Garthwaite, I.; Miles, C. O.; Ross, K. M.; Aggen, J. B.; Chamberlin, A. R.; Towers, N. R.; Dietrich, D. R., Congener-independent immunoassay for microcystins and nodularins. Environ Sci \& Tech 2001, 35, (24), 4849-56.

43. Samdal, I. A.; Ballot, A.; Lovberg, K. E.; Miles, C. O., Multihapten approach leading to a sensitive ELISA with broad cross-reactivity to microcystins and nodularin. Environ Sci \& Tech 2014, 48, (14), 8035-43.

44. Guo Y. C.; Lee A. K.; Yates R. S.; Liang S.; Rochelle P. A., Analysis of Microcystins in Drinking Water by ELISA and LC/MS/MS. J Am Water Works Assoc 2017, 109, (3), 13-25.

45. Association of Public Health Laboratories A Freshwater Algal Toxin Guidance Document for Public Health Laboratories (2017). https://www.aphl.org/aboutAPHL/publications/Documents/EH2017May-HAB-Toolkit.pdf
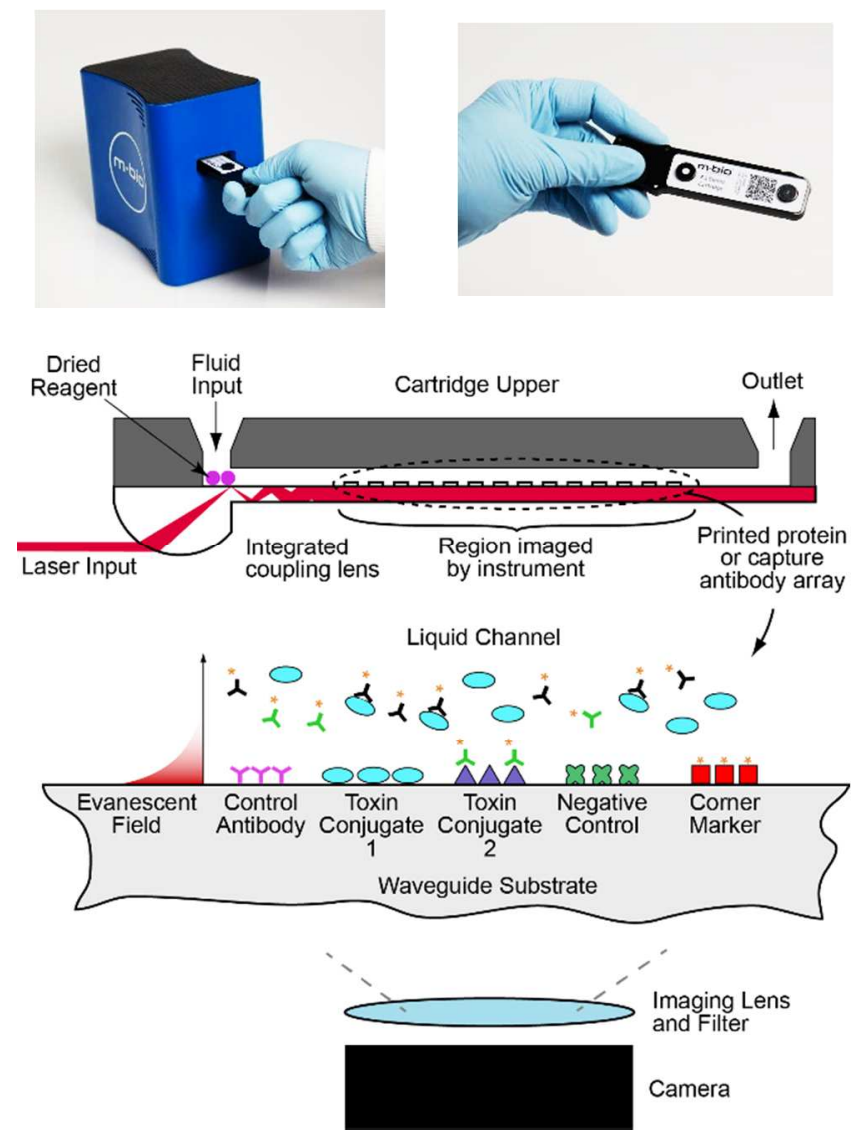
Figure 1. (Top) MBio reader and cartridge. (Bottom)

Schematic of LightDeck ${ }^{\circledR}$ technology elements.
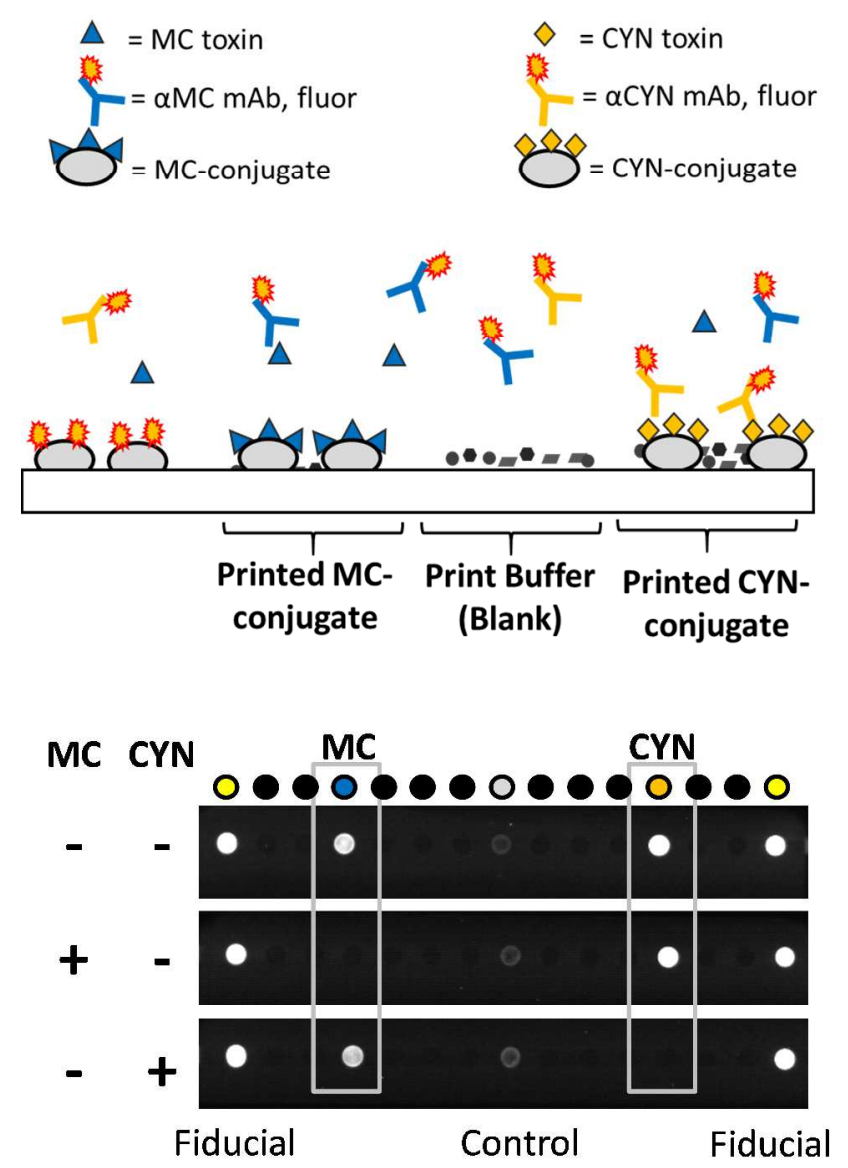

Figure 2. (Top) Cross-sectional schematic of the competitive immunoassay array concept. Not all array elements are represented. (Bottom) Representative array images for different assay conditions. A 1x15 spot array is printed. MC and CYN toxin-conjugate spots are indicated. Other spots in the array are print buffer blanks and process / fluidics controls. Array spots are $\sim 0.6 \mathrm{~mm}$ diameter on a $1.25 \mathrm{~mm}$ spot-to-spot grid spacing. 

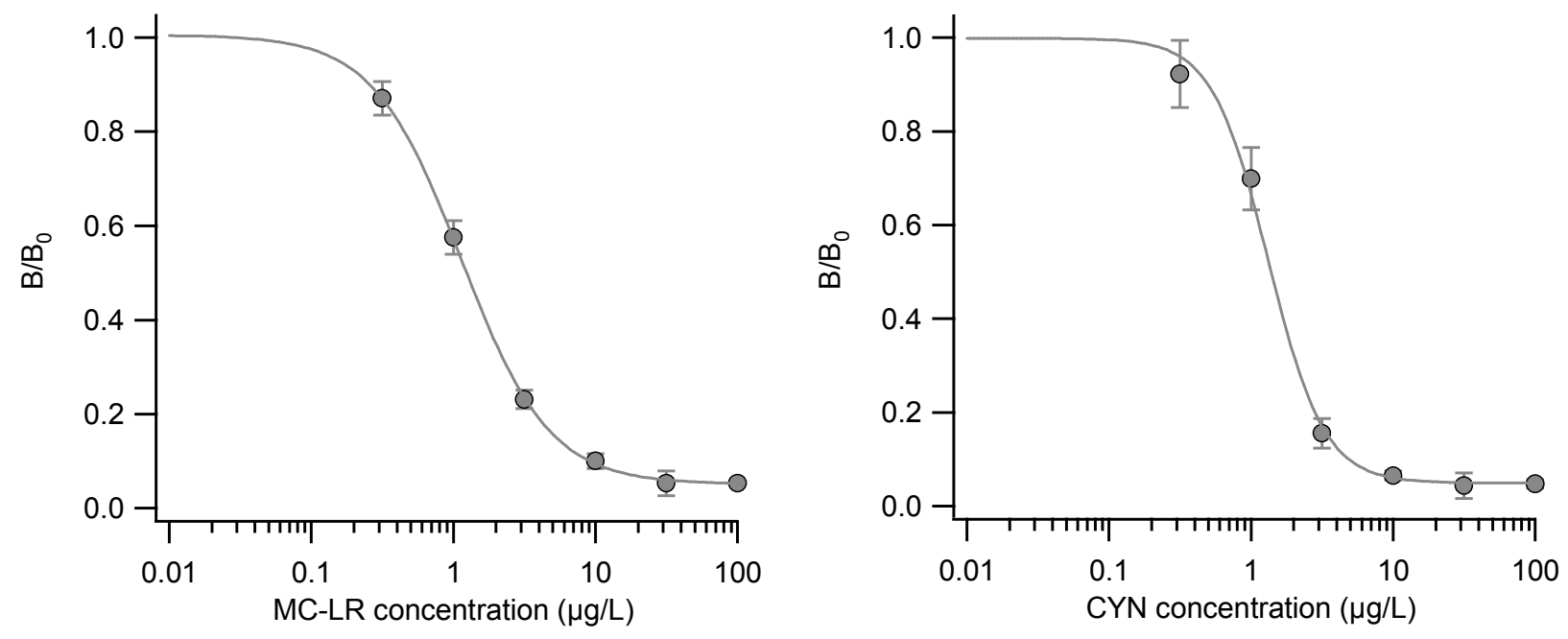

Figure 3. MC and CYN standard curves generated using certified reference materials from the NRCC in reagent water using the 10 -minute $\mathrm{MBio} \mathrm{MC} / \mathrm{CYN}$ assay cartridge. Each point is the average of 3 replicates. Error bars are \pm one standard deviation. Data are plotted with a 4-parameter logistic fit.

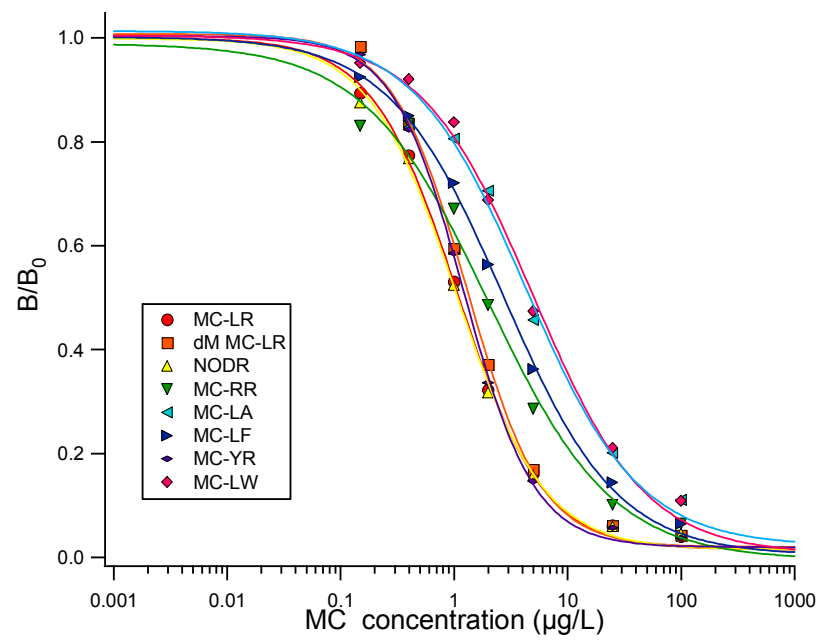

\begin{tabular}{|c|c|}
\hline Congener & MBio \\
\hline MC-LR & $100 \%$ \\
\hline dM MC-LR & $83 \%$ \\
\hline NODR & $100 \%$ \\
\hline MC-RR & $53 \%$ \\
\hline MC-LA & $28 \%$ \\
\hline MC-LF & $40 \%$ \\
\hline MC-YR & $83 \%$ \\
\hline MC-LW & $26 \%$ \\
\hline
\end{tabular}

Figure 4. Microcystin congener standards run in serial dilutions on the MBio MC/CYN cartridge. Each symbol is the average of triplicate cartridges. Four parameter logistic fits were applied to each congener dilution series. 
Table 1. Comparison of Lysis Methods

\begin{tabular}{|c|c|c|c|}
\hline Organism: & \multicolumn{2}{|c|}{ Microcystis $^{1}$} & $C y l^{2}$ \\
\hline Identifier: & $\begin{array}{l}\text { UTEX } \\
2385\end{array}$ & $\begin{array}{l}\text { UTEX } \\
2063\end{array}$ & $\begin{array}{c}\text { UTEX } \\
942\end{array}$ \\
\hline $\begin{array}{l}\text { Cell Conc. } \\
(\text { cells } / \mu \mathrm{L}) \times 10^{4}\end{array}$ & 2.1 & 1.6 & 1.2 \\
\hline Method & \multicolumn{3}{|c|}{ Percent Lysis } \\
\hline 3X Freeze-Thaw & $62 \%$ & $94 \%$ & $76 \%$ \\
\hline MBio Mechanical & $84 \%$ & $95 \%$ & $99 \%$ \\
\hline
\end{tabular}

${ }^{1}$ Microcystis aeruginosa

${ }^{2}$ Cyl. $=$ Cylindrospermopsis sp.

Table 2. Comparison of Lysis Methods with Natural Water Samples

\begin{tabular}{|c|c|c|c|}
\hline Organism: & Aphanizomenon & Anabaena & Microcystis $^{I}$ \\
\hline Cell Conc. & 1.3 & 0.3 & 24 \\
\hline cells $/ \mu \mathrm{L}) \times 10^{4}$ & \multicolumn{3}{|c|}{ Percent Lysis } \\
\hline Method & \multicolumn{3}{|c|}{$98.7 \%$} \\
\hline 3X Freeze-Thaw & $99.8 \%$ & $98.4 \%$ & $99.9 \%$ \\
\hline
\end{tabular}

Microcystis aeruginosa

Table 3. Microcystin Detection, Lake Erie

\begin{tabular}{|c|c|c|}
\hline Sample Name & $\begin{array}{c}\text { MBio } \\
(\boldsymbol{\mu} \mathbf{g} / \mathbf{L})\end{array}$ & $\begin{array}{c}\text { ADDA } \\
\text { ELISA } \\
(\boldsymbol{\mu g} / \mathbf{L})\end{array}$ \\
\hline GR1, Week 0 & $<0.6$ & 0.2 \\
\hline GR1, Week 4 & $2.4 \pm 0.1$ & 2.1 \\
\hline MB20, Week 0 & $<0.6$ & 0.2 \\
\hline 7M, Week 0 & $>4.0$ & $>5.0$ \\
\hline
\end{tabular}




\begin{tabular}{|c|c|c|}
\hline 7M, Week 1 & $<0.6$ & 0.2 \\
\hline 4P, Week 0 & $<0.6$ & $<0.15$ \\
\hline 4P, Week 1 & $<0.6$ & 0.4 \\
\hline CRIB, Week 1 & $<0.6$ & 0.5 \\
\hline CRIB, Week 4 & $2.0 \pm 0.1$ & 1.8 \\
\hline 8M, Week 1 & $<0.6$ & 0.3 \\
\hline MB18 Week 4* & $6.4 \pm 2.0$ & 6.7 \\
\hline 8M, Week 4* & $4.5 \pm 0.2$ & 6.4 \\
\hline Buoy (EW 5), Week 4* & $4.8 \pm 1.0$ & 7.9 \\
\hline
\end{tabular}

* These samples were diluted 1:10 to bring into assay range; reported results correct for the dilution. Standard deviations of the results on the MBio assay are reported for three replicates samples within the quantitative range.

Table 4. Microcystin Detection, Sandusky Bay

\begin{tabular}{|c|c|c|}
\hline Sample Name & MBio $(\mu \mathrm{g} / \mathbf{L})$ & ADDA ELISA $(\mu \mathrm{g} / \mathbf{L})$ \\
\hline EC Station 1163, Week 3 & $1.5 \pm 0.2$ & 2.1 \\
\hline EC Station 1163, Week 5 & $<0.6$ & 1.8 \\
\hline ODNR 1, Week 1* & $2.7 \pm 0.2$ & 6.5 \\
\hline ODNR 1, Week 3* & $2.8 \pm 0.6$ & 2.4 \\
\hline ODNR 2, Week 1 & $1.8 \pm 0.1$ & 6.1 \\
\hline ODNR 2, Week 3* & $3.3 \pm 0.6$ & 6.0 \\
\hline ODNR 2, Week 5* & $2.5 \pm 0.1$ & 0.7 \\
\hline ODNR 4, Week 1 & $0.6 \pm 0.4$ & 4.1 \\
\hline ODNR 4, Week 5 & $2.0 \pm 0.2$ & 3.1 \\
\hline ODNR 6, Week 1 & $2.0 \pm 0.1$ & \\
\hline
\end{tabular}




\begin{tabular}{|c|c|c|}
\hline ODNR 6, Week 3* & $2.6 \pm 0.9$ & 6.2 \\
\hline ODNR 6, Week 5* & $2.9 \pm 0.3$ & 1.3 \\
\hline Channel Bells, Week 1 & $1.0 \pm 0.2$ & 0.3 \\
\hline Channel Bells, Week 3 & $<0.6$ & 0.5 \\
\hline Channel Bells, Week 5 & $<0.6$ & 4.8 \\
\hline Buoy 2, Week 1 & $2.4 \pm 0.2$ & 5.2 \\
\hline Buoy 2, Week 3* & $2.1 \pm 0.1$ & 3.2 \\
\hline Buoy 2, Week 5 & $1.6 \pm 0.1$ & 6.9 \\
\hline Edison Bridge, Week 3* & $2.6 \pm 0.7$ & 6.5 \\
\hline Edison Bridge, Week 5* & $2.5 \pm 0.6$ & \\
\hline
\end{tabular}

* These samples were diluted 1:10 to bring into assay range; reported results correct for the dilution. Standard deviations of the results on the MBio assay are reported for three replicates samples within the quantitative range. 